\title{
Household Air Pollution and High Blood Pressure: A Secondary Analysis of the 2016 Albania Demographic Health and Survey Dataset
}

\author{
Mustapha S. Abba ${ }^{1, *(D)}$, Chidozie U. Nduka ${ }^{1}$, Seun Anjorin ${ }^{1}$ and Olalekan A. Uthman ${ }^{2,3}$ (D) \\ 1 Division of Health Sciences, Warwick Medical School, The University of Warwick, Coventry CV4 7AL, UK; \\ c.nduka@warwick.ac.uk (C.U.N.); seun.anjorin@warwick.ac.uk (S.A.) \\ 2 Warwick Centre for Global Health, Division of Health Sciences, University of Warwick Medical School, \\ Coventry CV4 7AL, UK; olalekan.uthman@warwick.ac.uk \\ 3 Division of Epidemiology and Biostatistics, Department of Global Health, Faculty of Health Sciences, \\ Stellenbosch University, Francie van Zijl Drive, Tygerberg, Cape Town 7505, South Africa \\ * Correspondence: mustapha.abba@warwick.ac.uk
}

check for updates

Citation: Abba, M.S.; Nduka, C.U.; Anjorin, S.; Uthman, O.A. Household Air Pollution and High Blood Pressure: A Secondary Analysis of the 2016 Albania Demographic Health and Survey Dataset. Int. J. Environ. Res. Public Health 2022, 19, 2611. https://doi.org/10.3390/ ijerph19052611

Academic Editors: Carla Viegas and Elisabete Carolino

Received: 21 December 2021

Accepted: 18 February 2022

Published: 24 February 2022

Publisher's Note: MDPI stays neutral with regard to jurisdictional claims in published maps and institutional affiliations.

Copyright: () 2022 by the authors. Licensee MDPI, Basel, Switzerland. This article is an open access article distributed under the terms and conditions of the Creative Commons Attribution (CC BY) license (https:/ / creativecommons.org/licenses/by/ $4.0 /)$.

\begin{abstract}
Background: Hypertension is a significant public health problem in low- and middleincome countries (LMICs). This study aimed to examine the association between household air pollution (HAP) and blood pressure using data from the 2016 Albania Demographic Health and Survey (DHS). Methods: We computed the odds ratio (OR) for the prevalence of hypertension between respondents exposed to clean fuels (e.g., electricity, liquid petroleum gas, natural gas, and biogas) and respondents exposed to polluting fuel (e.g., kerosene, coal/lignite, charcoal, wood, straw/shrubs/grass, and animal dung). Result: The results show that participants exposed to household polluting fuels in Albania were 17\% more likely to develop hypertension than those not exposed to household air pollution (OR $=1.17,95 \%$ CI 1.10 to 1.24$)$. Subgroup analysis revealed that the odds of hypertension were more significant among women $(\mathrm{OR}=1.22,95 \% \mathrm{CI} 1.13$ to 1.31$)$, rural residents $(\mathrm{OR}=1.12,95 \% \mathrm{CI} 1.04$ to 1.22$)$, and participants aged $>24$ years $(\mathrm{OR}=1.35,95 \% \mathrm{CI} 1.12$ to 1.62) who were exposed to household polluting fuels compared to their counterparts who were not exposed. In summary, the results of the study show significant associations between household air pollution and hypertension risk overall, especially among women, rural dwellers, and people aged $>24$ years in Albania. Conclusion: In this study, an association between household air pollution and the risk of hypertension was found, particularly among low-income households, those with no education, women, and those who live in rural areas.
\end{abstract}

Keywords: hypertension; high blood pressure; household air pollution; polluting fuels; Albania; lowand middle-income countries

\section{Introduction}

High blood pressure remains a public health problem in low- and middle-income countries (LMICs). It is a significant risk factor for cardiovascular disorders, including stroke and coronary heart disease [1-4].

In 2015, hypertension affected 1.13 billion individuals worldwide and resulted in 9.4 million deaths [5,6]. By 2025, the prevalence is projected to increase by $30 \%$ according to the World Health Organization [7]. Hypertension is projected to increase with growing population density and ageing in males and females [8,9]. The prevalence is high in Albania, especially among older adults; it is the primary driver of death and disability [10]. The environment is known to influence an individual's health outcome; for example, a good and secure environment will improve one's quality of life $[7,11]$. However, as a result of globalisation and industrialisation, the environment/home is currently a source of air pollutants that significantly affect the health and well-being of individuals, particularly 
in low- and middle-income countries [7,12]. Notably, the automotive industry and the establishment of factories have contributed to air pollution, especially in cities where most of the population reside. This development influenced the emergence of many diseases that pose high risks to life [12]. Therefore, protecting the environment and the air is the responsibility of every individual.

Clean air is considered one of the essential human health and well-being requirements [13]. However, in 2016, more than $90 \%$ of the world population was exposed to air quality levels that exceeded the World Health Organization (WHO) Air Quality Guideline limits [14]. Air pollution is the fourth most significant overall risk factor for human health globally, following high blood pressure, dietary risks, and smoking [15]. It has been associated with three of the leading causes of death worldwide, with significant shares in air-pollution-related mortality: stroke $(26 \%)$, ischemic heart disease $(20.2 \%)$, and primary cancer of the trachea, bronchus, and lung $(19 \%)[16,17]$. Air pollution has been linked to 7 million deaths globally and more than 100 million disability-adjusted life years (DALYs) annually [18].

Household air pollution is mainly generated by the utilisation of inefficient household combustion for cooking, heating, and lighting solid biomass (e.g., wood, cow dung, charcoal, and crop residues), which is common in most LMICs, including Albania [19]. An elevated level of fine particulate matter (PM 2.5) is an emerging hypertension risk factor $[20,21]$. House air pollutants such as carbon monoxide (CO) and particulate matter (PM) are classified to be hazardous, resulting in morbidity and mortality [22]. The combustion of solid fuels increases the risk of developing cardiovascular diseases, including hypertension and other heart diseases, especially in LMICs [23,24]. In 2010, household air pollution from solid fuels accounted for 3.5 million deaths and $4.3 \%$ of global disability-adjusted life years [21]. An estimated 3 billion people are exposed to household air pollution (HAP) from cooking with solid fuels, and most deaths result from using bad fuels, especially in LMICs $[25,26]$. The inhalation of several air pollutants causes acute autonomic imbalance and promotes the release of a variety of pro-oxidative, inflammatory, and haemodynamically active mediators into systemic circulation [21]. Consequently, numerous adverse responses, including elevations in blood pressure (BP), can instigate other cardiovascularrelated disorders such as myocardial infarction, stroke, heart failure exacerbation, arrhythmia, and cardiovascular-related death $[22,26,27]$. Higher PM and BP levels are individually linked to premature morbidity and mortality. The biological interconnection between these two risk factors and air pollution causes a significant threat to global public health [21].

High blood pressure and air pollution were found to be significant risk factors that cause the most deaths and disabilities in Albania. At the same time, ischemic heart disease and stroke remain the top causes of death, according to the Institute of Health Metrics and Evaluation (IHME) report [28]. Socioeconomic changes in the early 1990s resulted in increasing air pollution in Albania [21].

Although many efforts have been made to promote the use of clean fuels, nearly 2.7 billion people lack access to clean cooking facilities, relying on biomass, coal, or kerosene to meet their most basic energy needs [29]. The percentage of the population with access to clean fuels and technologies is increasing in most parts of the world. However, the rate of increase is not commensurate with population growth in most low- and middle-income countries, which potentially suggests there will be a rise in the prevalence of hypertension in most low- and middle-income countries [14]. Available evidence demonstrates the impact of ambient air pollution and its association with cardiovascular diseases, which has been well studied in high-income countries with consistent findings [30,31] However, indoor air pollution is an emerging risk factor for cardiovascular disease in LMICs, including Albania [32]. The aetiology of hypertension and its associations with indoor pollution is not well researched. Therefore, this study aims to provide additional evidence and new insights into new preventive measures that will reduce the impact of indoor air pollution in resource-limited settings. 


\section{Methods}

\subsection{Study Design and Sampling Technique}

This study was based on the secondary analyses of cross-sectional, population-based data from the 2018 Albania Demographic and Health Survey (DHS). The survey was conducted to collect data on demographic, environmental, socioeconomic, and health issues (family planning, infertility, immunisation, and the nutritional and health status of children, mothers, and fathers). The sample for the 2018 Albania DHS was nationally representative and covered the entire population in the country. The data collection procedures used have been published elsewhere. Data were collected by conducting face-to-face interviews with women and men who met the eligibility criteria. This study is based on an analysis of existing survey data with all identifier information removed. All study participants gave informed consent before participation, and all data were collected confidentially.

This analysis used cross-sectional data from the most recent 2018 Albania DHS. DHSs are nationally representative household surveys that provide information on a wide range of monitoring and impact evaluation indicators in a population, including nutrition, health, and other vital characteristics. The surveys have large sample sizes (usually between 5000 and 30,000 households). A DHS is conducted approximately every five years to allow for comparisons to be made over time.

In a DHS, the sample is generally representative at the national, residential (urban or rural), and regional levels. The survey utilises a stratified two-stage cluster design. Enumeration areas (EAs) are drawn from a census file during the first stage. In each EA selected, the second stage involves drawing a sample of households from an updated list of households. The national statistical office typically implements a DHS in a country, with data collection lasting between 5 and 6 months.

\subsection{Outcome Variable}

This study's primary outcome was hypertension, which included respondents who had a systolic blood pressure $>140 \mathrm{mmHg}$, diastolic blood pressure $>90 \mathrm{mmHg}$, or who were taking anti-hypertensive drugs at the time of the survey. Blood pressure was measured three times in 10-min intervals with small, medium, and large cuff sizes depending on the cuff size of the respondent. The average of the second and third measurements was used to categorise hypertension [33].

\subsection{Exposure Variable}

Exposure to household air pollution was grouped into two categories in this analysis based on exposure to cooking smoke: "clean fuels", including electricity, liquid petroleum gas (LPG), natural gas, and biogas, and "polluting fuels", including kerosene, coal/lignite, charcoal, wood, straw/shrubs/grass, and animal dung.

\subsection{Control Variables}

The following individual-level factors were included in the study: sex of the respondent (male versus female), respondents' age in years, educational attainment (no education, primary school, secondary school, or higher); marital status (never married, currently married, or ever married), occupation (working versus not working), cigarette smoking (yes versus no), health insurance (yes versus no), problems getting the money needed for treatment (yes versus no), media access (radio, television, or magazine), and indoor air pollution (cooking fuel type: low-pollution fuel or high-pollution fuel). Weight was measured to the nearest $0.5 \mathrm{~kg}$ with subjects in light clothing, and height was measured to the nearest $0.1 \mathrm{~cm}$. Body mass index (BMI) was calculated and categorized as underweight $\left(<18.5 \mathrm{~kg} / \mathrm{m}^{2}\right)$, overweight $\left(25-29.9 \mathrm{~kg} / \mathrm{m}^{2}\right)$, and obese $\left(\geq 30 \mathrm{~kg} / \mathrm{m}^{2}\right)$. The DHS did not collect direct information on household income and expenditure. We used the DHS wealth index as a proxy indicator for the socioeconomic position of the participants. 


\subsection{Statistical Analysis}

The analytical approach included descriptive as well as bivariable and multivariable analyses. The descriptive statistics show the distribution of respondents by the key variables. Values are expressed as absolute numbers (percentages) and means (standard deviation) for categorical and continuous variables. Individual weights were used for descriptive statistics in this study. We computed the odds ratio (OR) for the prevalence of hypertension between respondents exposed to clean fuels and respondents exposed to polluting fuel. An OR more significant than 1 suggested hypertension prevalence estimates were more prevalent among respondents exposed to polluting fuels. Conversely, a value less than 1 indicated that the hypertension prevalence estimates were more prevalent among respondents exposed to/using bad/polluting fuels, in addition to estimating the association between indoor air pollution and hypertension for all participants. The association was stratified by age, sex, educational attainment, occupation, body mass index category, and the place of residence of the participants. The life course association between indoor air pollution and hypertension was equally examined.

Next, we used bivariable analyses to examine the association between each variable and the dependent variable of high blood pressure. Contingency tables were analysed using the Pearson $\chi^{2}$ test or Fisher exact test. Multivariable logistic regression analyses were used to examine the net effects of the explanatory variables on the dependent variables. For multivariate analyses, household air pollution and other control variables listed above that were significant in the bivariable study $(p<0.05)$ were included in the regression model in a single block to control for possible confounding factors between them. The magnitude and direction of association were expressed in the adjusted odds ratios, and significant levels were defined as $p$-values. Regression diagnostics were used to judge the goodness-of-fit of the model. They included the tolerance test for multicollinearity, its reciprocal variance inflation factors (VIFs), the presence of outliers, and estimates of adjusted $\mathrm{R}$ square of the regression model. In addition, the Hosmer-Lemeshow goodness-of-fit test was used. None of the results of the tests provided any cause for concern. Thus, the models provided robust and valid results. The significance tests were two-tailed, and statistical significance was defined at the alpha level of 0.05 . Stata 17 was used for all analyses.

\section{Results}

\subsection{Sample Characteristics}

The characteristics of the participants are summarised in Table 1 . The prevalence of hypertension was $29.9 \%$, and the number of respondents with blood pressure sampled in Albania included in the analysis was 20,846. Many of the respondents were females (71.3\%); in comparison, $28.9 \%$ of the respondents were males. More than half of the respondents had secondary or higher education (53\%), while $47 \%$ either had no education or primary school education only. The majority of the respondents belonged to the $45-54$ age group $(25 \%)$. In comparison, $13 \%$ of the respondents belonged to the $55-64$ age group. About $28 \%$ of the respondents in Albania belonged to the poorest wealth quintile, while $11 \%$ belonged to the wealthiest quintile. A total of $59.1 \%$ of the respondents were not working, while $40.8 \%$ reported that they were working. Approximately $40 \%$ of the respondents had a normal weight, while $57 \%$ were either overweight or obese. About $54 \%$ of the participants lived in rural areas, while $45 \%$ lived in urban areas. Respondents exposed to household air pollution (bad fuel) in Albania were 16.5\% more likely to develop hypertension than respondents not exposed to house air pollution or respondents who used clean fuel. 
Table 1. Summary of Sample Characteristics of Survey Data in Albania.

\begin{tabular}{|c|c|c|c|c|c|}
\hline & & & Normotensive & Hypertensive & $p$-Value \\
\hline & Number & Percentage & Percentage \% & Percentage \% & \\
\hline Sex & & & & & 0.000 \\
\hline Male & 5988 & 28.72 & 68.6 & 31.4 & \\
\hline Female & 14,858 & 71.28 & 70.7 & 29.2 & \\
\hline Education & & & & & 0.000 \\
\hline No education & 190 & 0.91 & 70.5 & 29.5 & \\
\hline Primary & 9593 & 46.04 & 64.0 & 36.1 & \\
\hline Secondary+ & 11,054 & 53.05 & 75.6 & 24.4 & \\
\hline Wealth & & & & & 0.000 \\
\hline Poorest & 5828 & 27.96 & 66.7 & 33.2 & \\
\hline Poorer & 5027 & 24.11 & 68.7 & 31.2 & \\
\hline Middle & 4075 & 19.55 & 71.04 & 28.9 & \\
\hline Richer & 3526 & 16.91 & 72.77 & 27.2 & \\
\hline Richest & 2390 & 11.47 & 75.6 & 24.3 & \\
\hline Not Working & & & & & 0.000 \\
\hline Working & 8515 & 40.8 & 27.9 & 12.93 & \\
\hline Not working & 12,331 & 59.1 & 71.35 & 16.9 & \\
\hline BMI & & & & & 0.000 \\
\hline Underweight & 503 & 7.4 & 91.55 & 7.35 & \\
\hline Normal weight & 8252 & 40.3 & 84.01 & 15.98 & \\
\hline Overweight & 7166 & 35.0 & 66.32 & 33.67 & \\
\hline Obese & 4519 & 22.10 & 47.9 & 52.02 & \\
\hline Place of Residence & & & & & 0.000 \\
\hline Rural & 11,303 & 54.2 & 68.34 & 31.65 & \\
\hline Urban & 9543 & 45.7 & 72.2 & 27.77 & \\
\hline Age of Households & & & & & 0.000 \\
\hline 15 to 24 & 4511 & 21.6 & 93.48 & 6.51 & \\
\hline 25 to 34 & 4082 & 19.58 & 87.0 & 13.0 & \\
\hline 35 to 44 & 4091 & 19.62 & 73.5 & 26.5 & \\
\hline 45 to 54 & 5257 & 25.2 & 53.2 & 46.7 & \\
\hline 55 to 64 & 2905 & 13.93 & 36.0 & 63.9 & \\
\hline
\end{tabular}

The percentage of individuals with hypertension was higher among females exposed to/using bad fuel than males $(20.8 \%$ versus $9 \%, p<0.0001)$. Respondents with primary school education or no education were more likely to be exposed to indoor air pollution. The prevalence of hypertension was significantly higher in those with no education or primary school education than respondents with higher education ( $16.9 \%$ versus $12.9 \%)$. The prevalence of hypertension was significantly higher among the older age groups of 35 years and above. Approximately $12 \%$ of the $45-54$-year-old respondents were reported to be hypertensive, while the prevalence was lowest among the age group of 15-24-year-olds $(1.4 \%)$. The level of hypertension was higher among the poorest households than among the wealthiest households $(9.2 \%$ versus $3.0 \%, p<0.0001)$. The prevalence of hypertension was higher among respondents who were not working $(17.0 \%)$ than respondents who did work $(12.0 \%)$. Respondents who were overweight $(11.8 \%)$ and obese $(11.5 \%)$ were significantly more likely to be hypertensive than those who had a normal weight $(6.4 \%)$ and were underweight $(0.18 \% p<0.0001)$.

\subsection{Association between HAP and Hypertension}

The measure of association between house air pollution and hypertension is summarised in Figure 1 and Table 2. In the adjusted analysis, participants exposed to household air pollution were $17 \%$ more likely to have developed hypertension compared to those not exposed to indoor air pollution ( $\mathrm{OR}=1.17,95 \% \mathrm{CI} 1.10$ to 1.24$)$, such that 2310 of the 4906 
(32.0\%) individuals exposed to household air pollution had hypertension; in comparison, 3917 of the 9699 (28.8\%) individuals not exposed to HAP developed hypertension. When stratified by the sex of the participants, the association was only significant among women, such that women exposed to HAP were $22 \%$ more likely to have developed hypertension than women not exposed to HAP (OR $=1.22,95 \%$ CI 1.13 to 1.31$)$. In addition, the association was only significant among rural residents. Rural residents exposed to HAP were $12 \%$ more likely to develop hypertension than those not exposed to HAP (OR $=1.12,95 \% \mathrm{CI}$ 1.04 to 1.22). The association was more significant among participants aged 25 to 54 years old than among those aged 15 to 24 years old.

After controlling for other potential confounding variables in the adjusted analyses, the association between hypertension and household air pollution remained statistically significant (OR $=1.09,95 \%$ CI 1.01 to 1.19 ). The following traditional risk factors remained statistically significant: women were $20 \%$ less likely to be hypertensive (OR $=0.80,95 \%$ CI 0.74 to 0.86 ); participants with primary school education were $21 \%$ more likely to be hypertensive (OR $=1.21,95 \%$ CI 0.12 to 1.30 ) than those with secondary school or higher education; overweight and obese respondents were more likely to be hypertensive; and the odds of hypertension increased with increasing age.

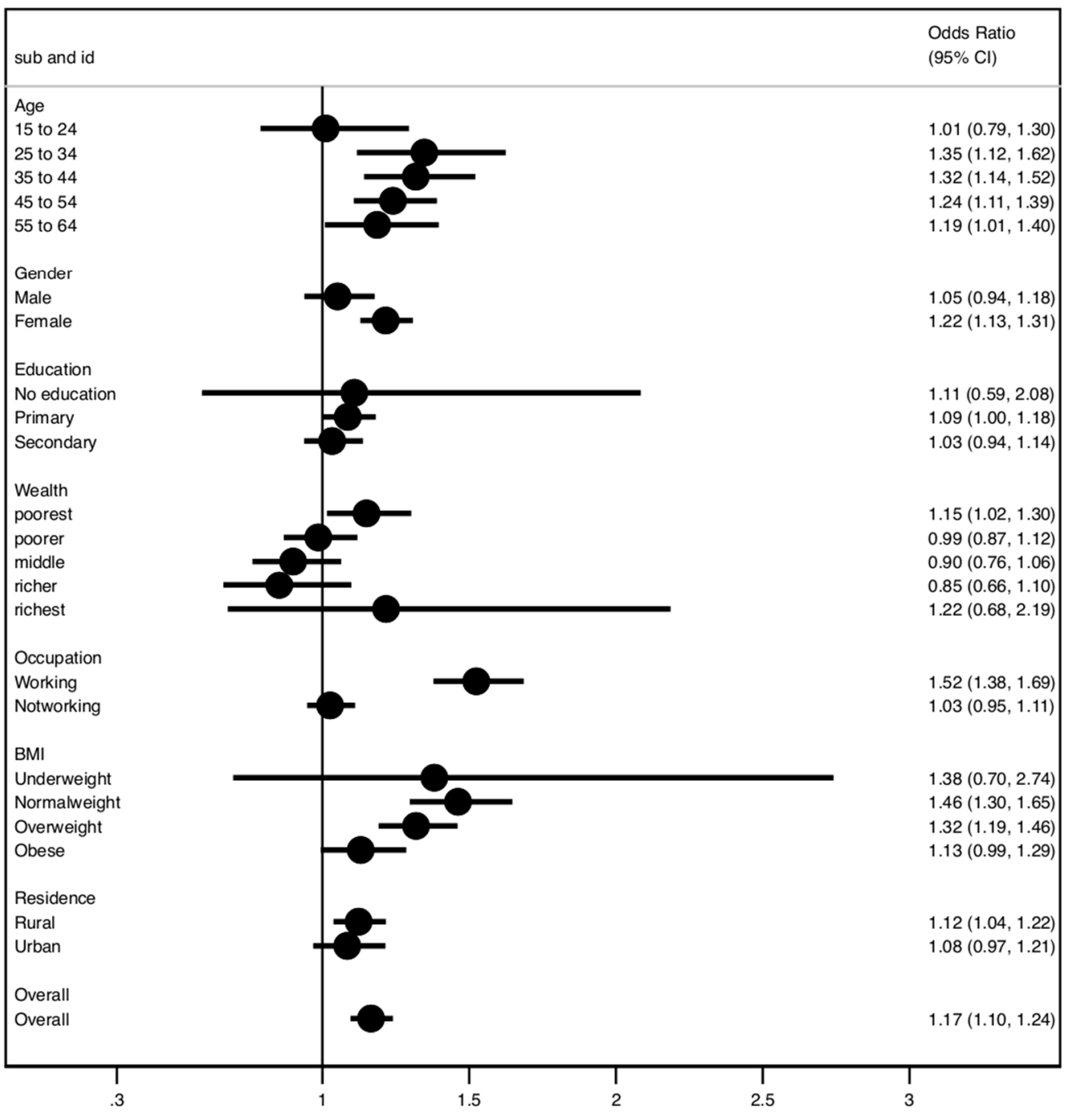

NOTE: Weights are based on user-defined quantities

Figure 1. Association between exposure to HAP and hypertension risk. 
Table 2. Unadjusted and adjusted odds ratios of the association between high blood pressure, indoor air pollution, and selected factors.

\begin{tabular}{|c|c|c|}
\hline & Unadjusted & Adjusted Association \\
\hline & OR $(95 \% \mathrm{CI})$ & OR $(95 \%$ CI $)$ \\
\hline \multicolumn{3}{|l|}{ Household air pollution } \\
\hline Clean vs. unclean & 1.17 (1.10 to 1.24$)$ & 1.09 (1.01 to 1.19$)$ \\
\hline \multicolumn{3}{|l|}{ Sex } \\
\hline Female vs. male & $0.90(0.84$ to 0.96$)$ & $0.80(0.74$ to 0.86$)$ \\
\hline \multicolumn{3}{|l|}{ Education } \\
\hline No education & 1.29 (0.94 to 1.77$)$ & $1.20(0.84$ to 1.71$)$ \\
\hline Primary & 1.75 (1.65 to 1.86$)$ & $1.21(1.12$ to 1.30$)$ \\
\hline Secondary+ & 1 (reference) & 1 (reference) \\
\hline \multicolumn{3}{|l|}{ Wealth } \\
\hline Poorest & 1.54 (1.39 to 1.72$)$ & 1.51 (1.29 to 1.76$)$ \\
\hline Poorer & 1.41 (1.26 to 1.58$)$ & 1.33 (1.16 to 1.53$)$ \\
\hline Middle & 1.27 (1.13 to 1.42$)$ & $1.21(1.06$ to 1.39$)$ \\
\hline Richer & $1.16(1.03$ to 1.31$)$ & $1.13(0.99$ to 1.31$)$ \\
\hline Richest & 1 (reference) & 1 (reference) \\
\hline \multicolumn{3}{|l|}{ Not Working } \\
\hline Not working vs. working & 0.87 (0.82 to 0.92$)$ & $1.02(0.95$ to 1.10$)$ \\
\hline \multicolumn{3}{|l|}{ BMI } \\
\hline Underweight & $0.42(0.30$ to 0.59$)$ & $0.84(0.59$ to 1.21$)$ \\
\hline Normal weight & 1 (reference) & 1 (reference) \\
\hline Overweight & $2.77(2.47$ to 2.88$)$ & $1.50(1.38$ to 1.64$)$ \\
\hline Obese & $5.70(5.24$ to 6.19$)$ & 2.67 (2.42 to 2.93$)$ \\
\hline \multicolumn{3}{|l|}{ Place of Residence } \\
\hline Rural vs. urban & $1.20(1.13$ to 1.28$)$ & 1.07 (0.98 to 1.16$)$ \\
\hline \multicolumn{3}{|l|}{ Age of Households } \\
\hline 15 to 24 & 1 (reference) & 1 (reference) \\
\hline 25 to 34 & $2.15(1.86$ to 2.50$)$ & $1.78(1.52$ to 2.09$)$ \\
\hline 35 to 44 & $5.17(4.5$ to 5.93$)$ & 3.72 (3.20 to 4.32$)$ \\
\hline 45 to 54 & $12.60(11.07$ to 14.36$)$ & $8.40(7.27$ to 9.69$)$ \\
\hline 55 to 64 & $25.49(22.15$ to 29.33$)$ & $16.86(14.47$ to 19.64$)$ \\
\hline
\end{tabular}

\section{Discussion}

The dataset used for this analysis was nationally representative population data from Albania, which we used to examine the association between indoor air pollution exposure in low- and middle-income countries. In Albania, the prevalence of developing hypertension was significantly higher among respondents exposed to house indoor air pollution. The odds of developing hypertension increased by $17 \%$ among respondents exposed to indoor air pollution than respondents not exposed. This study revealed that exposure to cooking solid fuels was significantly associated with increased blood pressure levels. Biomass fuel for cooking was associated with greater hypertension risk than the use of cleaner-burning LPG [11,27,34]. A study conducted by Li et al. found a positive association between increased indoor air pollution and solid fuel use and hypertension risk [34]. This could be due to high dust contents originating from local natural sources and metallurgical combinations [21]. An assessment revealed that dust levels in streets and in houses was approximately at the same level as those on roads; as such, more significant amounts of PM are emitted both at home and on the streets [35]. Conversely, Ofori et al. and Fatmi et al. found a negative association between indoor air pollution and hypertension; notably, this inconsistency might have been due to the type of fuel, location, and other confounding factors $[36,37]$.

The study demonstrated that the percentage of individuals with hypertension was higher among females exposed to household air pollution than males and females who 
used clean fuels for cooking. This finding is consistent with the study carried out by Arku and colleagues [25]. The result indicated a significant increase in blood pressure among women cooking with solid fuels, with substantially high blood pressure among rural women. Supporting this finding, Gordon et al. stated that women have a leading role in domestic cooking in more cultures than men do [19]. Balmes also found more substantial effect estimates for women due to intense daily cooking smoke exposure [38].

Socioeconomic status is a significant predictor of exposure to HAP in most cultures. In any context, less expensive fuel options are generally less efficient fuels, produce more household air pollution, and are used by people with the most poorly designed homes. In this study, the results demonstrate variations in population exposure to indoor air pollution across socioeconomic groups. Respondents with primary school or no education had a significantly higher prevalence of hypertension than respondents with higher education. Additionally, the prevalence of hypertension was higher among respondents in the poorest households than those from the wealthiest households. Supporting this finding, Apte and Salvi reported that the poor socioeconomic strata of society in rural settings live in poorly ventilated houses and use bad fuel as a source of energy, which contributes immensely to hypertension risk [11]. The situation is aggravated by inappropriate infrastructure such as electricity in Albania, making it difficult to use electricity as a source of energy. In contrast, houses in developed countries use clean liquefied petroleum gas, natural gas, or electricity for cooking. Many of these houses are well ventilated and also have green areas and fitted air conditioners.

The prevalence of hypertension was more significant among respondents not working than respondents who worked in Albania. Most workers live in the cities, can afford clean fuel as their energy source, and access good health care. Indoor air pollution has the most significant impact upon vulnerable populations within society due to limited resources to afford clean sources of energy and exposure due to underlying health conditions [39]. The prevalence of hypertension was significantly higher among the older age groups aged 35 and above. Giorgini et al. classified the elderly as vulnerable subjects with slightly higher blood pressure than younger groups following exposure to indoor air pollution [21]. Similarly, Deng et al. observed that older people exposed to biomass are more likely to develop hypertension in China [27].

The prevalence was significant among rural residents. Rural residents exposed to HAP were more likely to develop hypertension than those not exposed to HAP. Place of residence has been associated with HAP. Most of the population in LMICs live in rural and poor urban areas and mainly use biomass fuel as a source of their energy [40]. The prolonged inhalation of smoke from biomass cooking can increase the prevalence of hypertension [21].

\subsection{Strengths and Limitations}

This study used nationally representative data to evaluate the association between indoor air pollution and hypertension risk in a resource-limited setting. Despite the strengths of this study, we consider a number of limitations. For instance, more than 70\% of the respondents were women, which may explain why the association between HAP and hypertension was significant among women but not men.

In addition, we could not account for certain factors that might affect actual indoor air pollution and blood pressure measurement, including information on cooking time and the type of building and ventilation, which was shown to be linked to the prevalence of hypertension. The DHS data do not include information on other or secondary cooking fuels in the household. Some households reported using more than one fuel, which would lead to misclassification in the exposure definition and bias the estimated associations [41] The study did not include information on ambient air pollution, which may also be associated with high blood pressure. There was little or no information on the use of blood pressure medication. Lastly, several studies have used self-reported primary cooking fuel as a practical proxy for HAP; this is an inherently limiting indicator [42]. For cooking, heating, and lighting, one-third of the world's population uses organic materials 
such as wood, dung, or charcoal (biomass fuel). This type of energy use is linked to high levels of indoor air pollution, an increase in the incidence of respiratory infections such as pneumonia, tuberculosis, and chronic obstructive pulmonary disease, low birth weight, cataracts, cardiovascular events, and all-cause mortality in both adults and children [43]. The mechanics underlying these connections are not completely known. Much of the health-related exposure to air pollution from cooking fuel happens outside of homes, not simply within them [44]. Solid cooking fuel is toxic enough to have a significant impact on ambient (outside) air pollution levels and, as a result, can induce illness far away from the source [44]. Carbon monoxide, formaldehyde, and other hazardous chemicals released by natural gas and propane burners can be toxic to people and pets. Cooking with a wood stove or fireplace can produce a lot of wood smoke, which can pollute both indoor and outdoor air [45].

\subsection{Policy Implications}

Indoor air pollution and the use of cooking fuels can be controlled by introducing clean fuel/electricity such as liquid petroleum gas (LPG), which is a fuel recognised to reduce HAP levels. Governments should adopt renewable energy incentives to reduce dependence on solid fuels [46]. The findings will inform future intervention studies and policy changes by generating knowledge to effectively control high blood pressure in lowand middle-income countries.

\section{Conclusions}

The study found an association between household air pollution and the risk of hypertension, particularly among low-income households, those with no education, women, and those who live in rural areas. The findings suggest that the risk of hypertension may be reduced by eliminating or reducing indoor air pollution, particularly among Albania's most vulnerable groups and those groups in other similar countries in resource-limited settings. One of the most significant contributions to residential air pollution is the use of bad fuels for cooking and heating. Therefore, to minimise house air pollution, it is imperative to create awareness about household air pollution and its health effects to reduce the risk of cardiovascular disease in the population at large. Major interventional strategies need to be implemented at various levels to reduce household air pollution and its effects on health. Research and consolidating nationwide data from all countries will help to generate regional data regarding household air pollution in different regions to inform policy and decision making through behavioural interventions and cost-effective methods to improve the types of fuels used for cooking and heating. We have merely defined household air pollution as the self-reported exposure to 'polluting fuels' indoors. Unfortunately, data on indoor air pollutant concentrations are not included in the Albania DHS dataset. Hence, this specific question could be the subject of further research in future studies.

Author Contributions: M.S.A., S.A. and O.A.U. conceived of the study; M.S.A. carried out the data extraction and coding; M.S.A. conducted the statistical analysis under the supervision of C.U.N. and O.A.U.; M.S.A. drafted the paper with contributions from the other researchers. All authors have read and agreed to the published version of the manuscript.

Funding: This research received no external funding.

Institutional Review Board Statement: We analysed existing survey data in which all personal information was encrypted. The Ethics Committee approved this study of the ICF Macro (Fairfax, VA, USA) and the National Ethics Committees in individual countries. Respondents gave their informed consent, and all information was collected confidentially. All methods were carried out in accordance with relevant guidelines and regulations, and data were sourced from the link below. The data supporting this article are available at: http:/ / dhsprogram.com/data/available-datasets.cfm (accessed on 16 June 2020).

Informed Consent Statement: Not applicable. 
Data Availability Statement: All methods were carried out in accordance with relevant guidelines and regulations, and data were sourced from the link below. The data supporting this article are available at: http:/ / dhsprogram.com/data/available-datasets.cfm (accessed on 16 June 2021).

Acknowledgments: The researchers are grateful to the DHS Program for the opportunity to work with the DHS data.

Conflicts of Interest: The authors declare no conflict of interest.

\section{References}

1. Campbell, N.R.; Lackland, D.T.; Lisheng, L.; Niebylski, M.L.; Nilsson, P.M.; Zhang, X.H. Using the Global Burden of Disease study to assist development of nation-specific fact sheets to promote prevention and control of hypertension and reduction in dietary salt: A resource from the World Hypertension League. J. Clin. Hypertens. 2015, 17, 165-167. [CrossRef]

2. Mozaffarian, D. Global Scourge of Cardiovascular Disease: Time for Health Care Systems Reform and Precision Population Health; American College of Cardiology Foundatiom: Washington, DC, USA, 2017.

3. Kearney, P.M.; Whelton, M.; Reynolds, K.; Muntner, P.; Whelton, P.K.; He, J. Global burden of hypertension: Analysis of worldwide data. Lancet 2005, 365, 217-223. [CrossRef]

4. Kumar, J. Epidemiology of hypertension. Clin. Queries Nephrol. 2013, 2, 56-61. [CrossRef]

5. Zhou, B.; Bentham, J.; di Cesare, M.; Bixby, H.; Danaei, G.; Cowan, M.J.; Paciorek, C.J.; Singh, G.; Hajifathalian, K.; Bennett, J.E. Worldwide trends in blood pressure from 1975 to 2015: A pooled analysis of 1479 population-based measurement studies with 19.1 million participants. Lancet 2017, 389, 37-55. [CrossRef]

6. Craig, L.S.; Gage, A.J.; Thomas, A.M. Prevalence and predictors of hypertension in Namibia: A national-level cross-sectional stu. PLoS ONE 2018, 13, e0204344. [CrossRef]

7. WHO. A Global Brief on Hypertension: Silent Killer, Global Public Health Crisis; World Health Day; WHO: Geneva, Switzerland, 2013.

8. Appelman, Y.; van Rijn, B.B.; Monique, E.; Boersma, E.; Peters, S.A. Sex differences in cardiovascular risk factors and disease prevention. Atherosclerosis 2015, 241, 211-218. [CrossRef] [PubMed]

9. Sarki, A.M.; Nduka, C.U.; Stranges, S.; Kandala, N.-B.; Uthman, O.A. Prevalence of hypertensionhypertension in low-and middle-income countries: A systematic review and meta-analysis. Medicine 2015, 94, e1959. [CrossRef] [PubMed]

10. Pirkle, C.M.; Ylli, A.; Burazeri, G.; Sentell, T.L. Social and community factors associated with hypertension awareness and control among older adults in Tirana, Albania. Eur. J. Public Health 2018, 28, 1163-1168. [CrossRef] [PubMed]

11. Apte, K.; Salvi, S. Household air pollution and its effects on health. F1000Research 2016, 5. [CrossRef]

12. Mecaj, S.; llano, I. The Issue of Air Pollution in Albania. In The Ninth International Conference on Eurasian Scientific Development; Proceedings of the Conference; Association for Advanced Studies and Higher Education GmbH: Vienna, Austria, 2016; pp. 216-222.

13. Juginović, A.; Vuković, M.; Aranza, I.; Biloš, V. Health impacts of air pollution exposure from 1990 to 2019 in 43 countries untries. Sci. Rep. 2021, 11, 22516. [CrossRef]

14. WHO. Ambient (Outdoor) Air Pollution. 2018. Available online: https://www.who.int/newsroom/factsheets/detail/ambient(outdoor)-air-quality-and-health (accessed on 5 December 2021).

15. Rafaj, P.; Kiesewetter, G.; Gül, T.; Schöpp, W.; Cofala, J.; Klimont, Z.; Purohit, P.; Heyes, C.; Amann, M.; Kleefeld, J.-B.; et al. Outlook for clean air in the context of sustainable development goals. Glob. Environ. Chang. 2018, 53, 1-11. [CrossRef]

16. WHO. Air Pollution. 2020. Available online: https://www.who.int/health-topics/air-pollution\#tab=tab_1 (accessed on 4 December 2021).

17. Lackland, D.T.; Weber, M.A. Global burden of cardiovascular disease and stroke: Hypertension at the core. Can. J. Cardiol. 2015, 31, 569-571. [CrossRef] [PubMed]

18. WHO. The Top 10 Causes of Death. 2020. Available online: https://www.who.int/news-room/fact-sheets/detail/the-top-10 -causes-of-death (accessed on 6 December 2021).

19. Gordon, S.B.; Bruce, N.G.; Grigg, J.; Hibberd, P.L.; Kurmi, O.P.; Lam, K.-B.H.; Mortimer, K.; Asante, K.P.; Balakrishnan, K.; Balmes, J. Respiratory risks from household air pollution in low- and middle-income countries. Lancet Respir. Med. 2014, 2, 823-860. [CrossRef]

20. Ibrahim, M.M. Hypertension in developing countries: A major challenge for the "future". Curr. Hypertens. Rep. 2018, 20, 38. [CrossRef] [PubMed]

21. Giorgini, P.; di Giosia, P.; Grassi, D.; Rubenfire, M.; Brook, R.D.; Ferri, C. Air pollution exposure and blood pressure: An updated review of the literature. Curr. Pharm. Des. 2016, 22, 28-51. [CrossRef]

22. Woolley, K.E.; Dickinson-Craig, E.; Bartington, S.E.; Oludotun, T.; Kirenga, B.; Mariga, S.T.; Kabera, T.; Coombe, A.; Pope, F.D.; Singh, A. Effectiveness of interventions to reduce household air pollution from solid biomass fuels and improve maternal and child health outcomes in low-and middle-income countries: A systematic review protocol. Syst. Rev. 2021, 10, 1-7. [CrossRef]

23. Mohapatra, I.; Das, S.C.; Samantaray, S. Health impact on women using solid cooking fuels in rural area of Cuttack district Odisha. J. Fam. Med. Prim. Care 2018, 7, 11.

24. Qiu, Y.; Yang, F.-A.; Lai, W. The impact of indoor air pollution on health outcomes and cognitive abilities: Empirical evidence from China. Popul. Environ. 2019, 40, 388-410. [CrossRef] 
25. Arku, R.E.; Ezzati, M.; Baumgartner, J.; Fink, G.; Zhou, B.; Hystad, P.; Brauer, M. Elevated blood pressure and household solid fuel use in premenopausal women: Analysis of 12 Demographic and Health Surveys (DHS) from 10countries'countries. Environ. Res. 2018, 160, 499-505. [CrossRef]

26. Lee, K.K.; Bing, R.; Kiang, J.; Bashir, S.; Spath, N.; Stelzle, D.; Mortimer, K.; Bularga, A.; Doudesis, D.; Joshi, S. Adverse health effects associated with household air pollution: A systematic review, meta-analysis, and burden estimate on study. Lancet Glob. Health 2020, 8, e1427-e1434. [CrossRef]

27. Deng, Y.; Gao, Q.; Yang, D.; Hua, H.; Wang, N.; Ou, F.; Liu, R.; Wu, B.; Liu, Y. Association between biomass fuel use and risk of hypertensionhypertension among Chinese older people: A cohort study. Environ. Int. 2020, 138, 105620. [CrossRef]

28. Institute of Health Metrics and Evaluation. IHME-Compare G; University of Washington: Washington, DC, USA, 2016.

29. IEAG Energy. $\mathrm{CO}_{2}$ Status Report 2017; International Energy Agency: Paris, France, 2018.

30. Painschab, M.S.; Davila-Roman, V.G.; Gilman, R.H.; Vasquez-Villar, A.D.; Pollard, S.L.; Wise, R.A.; Miranda, J.J.; Checkley, W.; CRONICAS Cohort Study Group. Chronic exposure to biomass fuel is associated with increased carotid artery intima-media thickness and a higher prevalence of atherosclerotic plaque. Heart 2013, 99, 984-991. [CrossRef] [PubMed]

31. Lim, Y.-H.; Kim, H.; Kim, J.H.; Bae, S.; Park, H.Y.; Hong, Y. Air pollution and symptoms of depression in elderly adults. Environ. Health Perspect. 2012, 120, 1023-1028. [CrossRef] [PubMed]

32. Samet, J.M.; Bahrami, H.; Berhane, K. Indoor air pollution and cardiovascular disease: New evidence from Iran. Circulation 2016, 133, 2342-2344. [CrossRef] [PubMed]

33. Chobanian, A.V. Prehypertension revisit. Hypertension 2006, 48, 812-814. [CrossRef] [PubMed]

34. Li, L.; Yang, A.; He, X.; Liu, J.; Ma, Y.; Niu, J.; Luo, B. Indoor air pollution from solid fuels and hypertension: A systematic review and metanalysis. Environ. Pollut. 2020, 259, 113914. [CrossRef]

35. Lika, M.; Çoku, A.; Nelaj, E. Health impact assessment of air pollution in some regions in Albania. J. Life Sci. $2012,6,1028$.

36. Ofori, S.N.; Fobil, J.N.; Odia, O.J. Household biomass fuel use, blood pressure and carotid intima media thickness: A cross sectional study of rural dwelling women in Southern Nigeria. Environ. Pollut. 2018, 242, 390-397. [CrossRef]

37. Fatmi, Z.; Ntani, G.; Coggon, D. Coronary heart disease, hypertension and use of biomass fuel among women: Comparative cross-sectional study. BMJ Open 2019, 9, e030881. [CrossRef]

38. Balmes, J.R. Household air pollution from domestic combustion of solid fuels and health. J. Allergy Clin. Immunol. 2019, 143, 1979-1987. [CrossRef]

39. Ferguson, L.; Taylor, J.; Davies, M.; Shrubsole, C.; Symonds, P.; Dimitroulopoulou, S. Exposure to indoor air pollution across socioeconomicsocio-economic groups in high-income countries: A scoping review of the literature and a modelling methodolody. Environ. Int. 2020, 143, 105748. [CrossRef] [PubMed]

40. Abtahi, M.; Koolivand, A.; Dobaradaran, S.; Yaghmaeian, K.; Mohseni-Bandpei, A.; Khaloo, S.S.; Jorfi, S.; Saeedi, R. National and sub-national age-sex specific and cause-specific mortality and disability-adjusted life years (DALYs) attributable to household air pollution from solid cookfuel use (HAP) in Iran, 1990-2013. Environ. Res. 2017, 156, 87-96. [CrossRef] [PubMed]

41. Piedrahita, R.; Johnson, M.; Bilsback, K.R.; L'Orange, C.; Kodros, J.K.; Eilenberg, S.; Naluwagga, A.; Shan, M.; Sambandam, S.; Clark, M. Comparing regional stove-usage patterns and using those patterns to model indoor air quality impacts. Indoor Air 2020, 30, 521-533. [CrossRef] [PubMed]

42. WHO. Burning Opportunity: Clean Household Energy for Health, Sustainable Development, and Wellbeing of Women and Children WellBeing; WHO: Geneva, Switzerland, 2016. Available online: www.who.int/airpollution/publications/burning_opportunities/en/ (accessed on 16 February 2022).

43. Fullerton, D.G.; Bruce, N.; Gordon, S.B. Indoor air pollution from biomass fuel smoke is a major health concern in the developing world. Trans. R. Soc. Trop. Med. Hyg. 2008, 102, 843-851. [CrossRef]

44. Smith, K.R.; Pillarisetti, A. Household Air Pollution from Solid Cook fuels and Its Effects on Health. In Injury Prevention and Environmental Health, 3rd ed.; Mock, C.N., Nugent, R., Kobusingye, O., Eds.; The International Bank for Reconstruction and Development/The World Bank: Washington, DC, USA, 2017; Chapter 7. Available online: https://www.ncbi.nlm.nih.gov/ books/NBK525225/ (accessed on 16 February 2022). [CrossRef]

45. WHO. Indoor Air Quality Guidelines: Household Fuel Combustion; WHO: Geneva, Switzerland, 2014.

46. McLean, E.V.; Bagchi-Sen, S.; Atkinson, J.D.; Ravenscroft, J.; Hewner, S.; Schindel, A. Country-level analysis of household fuel transitions. World Dev. 2019, 114, 267-280. [CrossRef] 